\title{
Networked Learning: Designing for adult literacy learners
}

\author{
ANA PINTO
}

\begin{abstract}
This paper reports on analysis of an online learning network catering for adult basic education. It introduces some key concepts from research on networked learning, as well as two complementary approaches that are useful to support and inform analysis and design of technology-enhanced environments. One approach is informed by ideas about the design of learning environments in which pedagogies are combined with complex technological arrangements. The other approach shows how ideas from urban and architectural design, particularly the work by Christopher Alexander on design patterns and pattern languages, can be used to support design for learning. Part of the argument for combining these two perspectives is that, in trying to manage the complex possibilities of new network technologies, pedagogical and humanistic ideals are easily damaged, forgotten or lost. The analytic work involves some methodological innovation, partly because of the data sources involved. It uses interviews as well as screenshots of web pages, other online artefacts and data logs; these sources allow the researcher to look 'beyond the screen' to reconstruct the deeper architecture of what has been created for, and by, the participants in the network. The preliminary outcomes show how connections can be drawn between some of the key qualities of what has been designed alongside the various configurations of things, places, tasks, activities, and people influencing learning. Eventually, what is learned from a case study is discussed with the aim of informing design of similar learning networks.
\end{abstract}

Literacy and Numeracy Studies 2014. @ 2014 ANA PINTO. This is an Open Access article distributed under the terms of the Creative Commons Attribution 4.0 Unported (CC BY 4.0) License (https://creativecommons.org/licenses/by/4.0/), allowing third parties to copy and redistribute the material in any medium or format and to remix, transform, and build upon the material for any purpose, even commercially, provided the original work is properly cited and states its license. 


\section{Introduction}

Networked learning is defined as 'Learning in which information and communication technology is used to promote connections: between one learner and other learners, between learners and tutors, between a learning community and its learning resources' (Goodyear, Banks, Hodgson and McConnell 2004:1). It can occur within formal educational contexts, but very often it transcends formal arrangements and/or involves informal and self-organised learning of various kinds. The ontology of networked learning is rooted in democratic ideals of inclusive education and its pedagogy, based heavily on collaborative dialogues, aligns well with the humanistic perspectives of Paulo Freire and others (McConnell, Hodgson and Dirckink-Holmfeld 2011). However, despite the fact that adult literacy learners are interested in and can benefit from using new information and communication technologies, networked learning opportunities within the domain of adult basic education $(\mathrm{ABE})$ are still very few and far between. Of course, there are a number of complex reasons for the slow take up of networked learning within $\mathrm{ABE}$, including issues of access, skills for participation, funding, teacher training, lack of research and evaluation of computer use, and so on. Notwithstanding the complexities behind all these issues, and as a way to contribute to research developments, this study explores the use of a design approach to promote and facilitate the creation of networked learning opportunities within the domain of adult basic education.

Designing such networked learning settings involves the complex intertwining of pedagogical, physical, digital and social aspects across many different layers and scales (Goodyear 2005, Goodyear and Retalis 2010). Research for design takes two main paths: understanding how people design for learning and helping them improve what they do, and analysing existing examples of networks to extract useful, reusable design ideas. The study presented in this paper is mainly concerned with the second of these two. This idea of reusing design knowledge originated in the field of architecture with Alexander's pattern languages theory (Alexander, Ishikawa and Silverstein 1977, Alexander 1979, 2006). Design patterns can be written to capture the design essence of very small things, as well as very large (from chairs and ornaments, through houses and cafes to city squares and neighbourhoods). Patterns can be 
combined into pattern languages, to express complex, multi-level or multi-layered designs. Alexander's writings also include subtle philosophical principles that help us understand why it is that designs which disregard human beings' deepest values and needs end up as failures (Goodyear, Thompson, Ashe, Pinto, Carvalho, Parisio, Parker, Schwendimann, Wardak and Yeoman, forthcoming). Thus, pattern languages theory offers powerful methodological and conceptual tools for analysing learning networks with the aim of capturing and sharing good design solutions to support the creation of productive technology enhanced learning environments.

\section{Literature review}

Literacy as a social practice is seen as part of everyday culturally and historically situated activities (Street 1984, Barton, Hamilton and Ivanic 1999). In contemporary society, new information and communication technologies have significantly changed the materiality of literacy, and multimodality largely shapes the possibilities and affordances of literacy practices (Barton and Hamilton 2005). Therefore, literacy practices, including networked learning, are part of a broader ecology where learning activity and technologies are inseparable and can only be understood in relation to one another. Only by restoring a 'thing status' to literacy can one account for the ability of literacy to 'travel, integrate and endure' beyond locales where social practices take place (Brandt and Clinton 2002: 337-338). As new information and communication technologies are integrated into everyday practices, potential learning opportunities become increasingly available through online networks. Not surprisingly, researchers have found that regardless of their literacy levels, most adults seem to be interested in using computers to engage in social networks to connect with friends and family (Chovanec and Meckelborg 2011, Smythe 2012). Further, research studies have indicated that online technologies can aid adult education even for those with the most limited skills and language proficiencies. Regrettably, in many cases, the lack of appropriate design represents a major barrier for adult literacy learners to be able to participate independently in online activities (Silver-Pacuilla 2008, Warschauer and Liaw 2010, Smythe 2012). A lack of research and evaluation of computer use within adult basic education that could provide guidance on content development and layout, as well as 
appropriate scaffolding to serve these users' needs are inhibiting the creation of such opportunities.

Learning networks involve both digital and material tools and artefacts, and activity is both online and in the 'physical' or 'offline' world. Researchers have been looking for ways to connect the social, physical, cultural, biological, and technical processes that influence and situate learning (Sorensen 2009, Fenwick 2012). The diffuse anywhere, anytime, anyhow character of networked learning adds a great deal of complexity to the creation of infrastructure, that is, 'the ways in which networked learning environments present themselves to potential users' (Jones and Dirckinck-Holmfeld 2009:14). This concept of infrastructure is a good metaphor to emphasise the interplay between human and non-human aspects in the constant dialectical processes involved in networked learning. Networked learning settings consist of the totality of resources made available for learning, and these include both what has been put in place by a teacher or designer, as well as knowledge objects produced by the learners. Tracing how designed features relate to one another within the overall architecture help understand their influence on learning. In this context, the notion of reification - 'the process of giving form to our experience by producing objects that congeal this experience into "thingness"' (Wenger 1998: 58) - can be very useful for understanding how meanings are negotiated around abstract representations in these highly mediated settings. Reified products that result from participants' agency constitute essential features that make the activities within the networks less ephemeral. Therefore, infrastructure for networked learning needs to be seen as a relational concept, as something that shapes and is shaped by the dynamic and always evolving relations between users and other non-human agents. As innovative online networks catering for adult literacy learners start being created, good design solutions can be captured and shared through design patterns and pattern languages.

\section{Analysing a learning network in the ABE field: the study and research design}

In this qualitative study, explanations of the design of a productive networked learning environment are provided through a case study. Case studies involve methods for collecting empirical materials and analysis processes in ways to promote the construction of consistent interpretations. Data sources included screenshots of 
web pages, and other online artefacts, data logs, and a semi-structured interview with one of the network's designers. A diagrammatic representation of the overall design of the network was produced along with the narrative case study account based on the analytical framework, the interview, and analysis of digital artefacts.

The study drew on an analytical framework (Goodyear and Carvalho 2013, Carvalho and Goodyear 2014) that integrates ideas and methods from pedagogy, design and architecture. The analytical framework focuses on the designed elements and their relationships to context, approaches to knowledge and knowing, and emergent activities. According to the framework, the architecture of networked learning involves three designable dimensions: a) physical architecture (set design) involves the digital and material spaces, both local and remote, as well as digital and physical resources that may constitute online networks; b) epistemic architecture (epistemic design) involves the design of tasks that need to be considered in relation to nested structures of sub-tasks and supra-tasks, as well as broader conceptualisations of knowledge and ways of knowing; c) social architecture (social design) involves interpersonal relationships and divisions of labour. Additionally, this framework draws attention to the importance of co-creation and co-configuration, that is, how participants' activities re-shape and re-organise the environment. By exploring all these dimensions key architectural qualities of online learning networks can be identified and abstracted (Pinto, Thompson, Jones and Clow 2014).

Two research questions drove the analytical investigation:

a) What are some of the key architectural qualities of the learning network?

b) How can analysis, coupled with different forms of representation, be effective in abstracting and communicating design solutions in ways to support the design activity of other people?

\section{The case study: NALA}

The National Adult Literacy Agency (NALA) is an Irish independent member-based organisation committed to adult literacy education. NALA has been supporting adult learners, tutors and literacy providers, and developing policy and research for over thirty years. Since 2000 it has been using a range of technologies in its 
distance learning service: free-phone tutoring, mailing printed material, radio and television programs, and more recently, using the Internet. The NALA website has been designed to cater for adult learners with a wide range of needs and interests, as well as their tutors.

For this paper, two analytic perspectives on the NALA learning network have been taken. One of these is quite conventional - at least it will be recognisable to researchers who are familiar with screen design, graphic design, layout etc., whether for websites or as part of the older tradition of page design for print materials. This perspective looks squarely at what is 'on the screen', analysing some key features from the specific perspective of learner needs in ABE. The second analytic perspective is more novel. It goes 'behind the screen' to excavate the deeper architecture of the learning network. As will be explained in more detail shortly, this deeper architecture can be thought of as involving epistemic, social and physical/digital components, and (especially) their integration. It is also important to say that what is seen on the screen cannot be divorced from the deeper architecture. In good designs, the two are intimately connected.

\section{Summary and discussion of outcomes from the analysis}

Figure 1 shows the homepage of the NALA website. The main part of the homepage is divided into three sections: header, intermediary, and bottom section. The header provides basic contact details (the name of the organisation, free-phone and MSN numbers, Irish map for the location of courses, and a search function) and the main navigation bar (Need Help, Literacy in Ireland, What we do, Support us, and Resources) provides access to all major additional pages. 

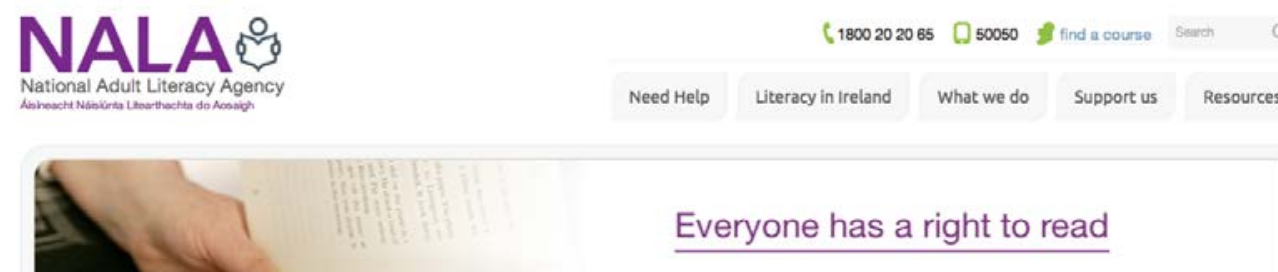

We believe literacy is an issue of national importance.

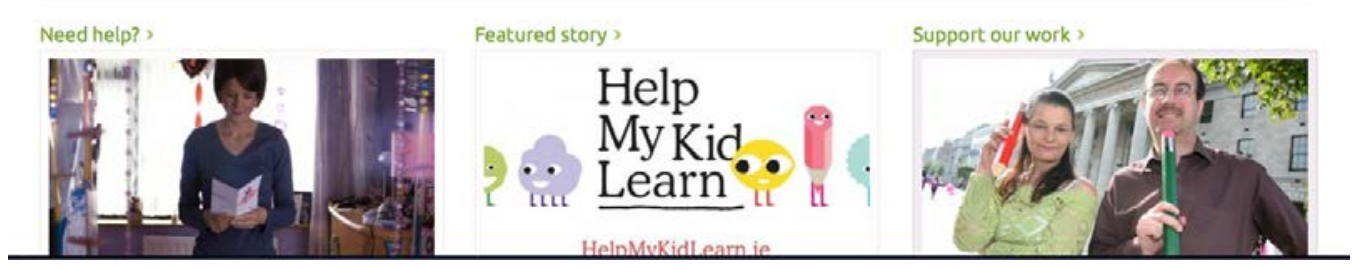

Figure 1: NALA's homepage

As simple as it may appear, the partial screenshot of NALA's homepage reflects the outcomes of careful design. The page layout is clean and functional in order to facilitate navigation by adult literacy learners. Written text is kept to a minimum and images and blank spaces help to give a clean yet friendly touch. One of the main functions of this page is to ensure learners realise that whatever their difficulties and interests may be, NALA is there to help them. In this context, the types of knowledge valued (epistemic design) and roles and division of labour (social design) can be inferred upfront from the elements shown in this page. For instance, the prominent headline 'Everyone has the right to read' (inclusiveness) and 'Help my Kid Learn' (family literacy) point to an approach to literacy that goes beyond the individual mechanics of reading and writing. Meanwhile, 'Need help?, 'Featured story' and 'Support our work' signal a collective and collaborative enterprise.

Scrolling down the page, there are links to secondary features such as a tutor's corner and student's corner, and an information box for learning about the 'latest news', 'upcoming events', recent Facebook posts, and E-zine subscriptions. Additionally, at the bottom of the page, there are links to NALA's social media sites (Facebook, Twitter, and YouTube), and, again, links to all major pages but with prominence given to the distance learning service. Facebook and 
Twitter are used to support and/or extend the activities hosted within the main site, while the dedicated YouTube site functions as an archive.

By using free digital platforms, software, and popular social media, NALA extends both its digital and physical spaces. For instance, television programs broadcast across Ireland become available for an international audience via NALA's dedicated YouTube page. In actuality, NALA offers learning opportunities for people everywhere. Although originally designed for Irish learners, the website can be accessed by anyone with an Internet connection. Once new online environments are deployed, their reach is extended to the world. The main difference is that within Ireland, learners can get extra support (e.g. freephone tutoring and learning material via postal services). But, again, non-Irish learners may be taking advantage of physical spaces and resources (including human) wherever they live.

\section{Looking behind the screen at the deeper architecture}

The features, tools and resources compose the infrastructure of the network, that is, its set design. Regarding epistemic design, knowledge in the learning network is of two kinds: (i) specialist knowledge involving multiple literacies, and (ii) tacit, everyday knowledge. Knowledge resources made available to the ABE community include health literacy, workplace literacy, financial literacy, and so on. In many cases set, social, and epistemic designs are very much entangled. For instance, NALA's set design relies on videos recorded by adult learners (social design) to portray literacy as everyday life-enhancing experiences (epistemic design). Such video recordings along with other resources produced by learners (e.g. 'A story with me in it') co-create and co-configure the existing design as they become accessible to all learners and tutors through the website.

Reconstructing the deeper architecture of the network takes time and care. By studying screens, following links and so on, one can begin to map the network infrastructure. One productive way I have found to do this is to sketch the emerging network architecture on a large 'writable wall' - see Figure 2.

The diagram in Figure 2 depicts the complexities of the various elements in the network, helping part of my reflections on how 
features relate to one another within the overall architecture. For instance, looking at 'Other Digital Spaces/distance educational service' (in the centre of the diagram) there is an element, Write On, which has connections spreading in many directions. In relation to NALA, Write On is a set design feature (e.g. a piece of software); an epistemic design feature (e.g. bringing together learning tasks associated with traditional and new literacies); and a social design feature (e.g. promoting independent learning). Interestingly, all these design dimensions (as well as co-creation and co-configuration) recur again within Write On.

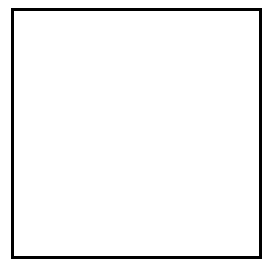

\section{Figure 2: NALA's overall architecture}

Following, three screen shots from Write On are presented. The first two are used just as a way of offering an insight into the overall design and to provide contextual background. The last one presents a more detailed analysis with the aim of illustrating some points discussed in the introductory part of this paper. The first screenshot, Figure 3, shows the 'Write On' Welcome page.

The design elements on the welcome page, a combination of video, audio, text, and image, are mainly concerned with ensuring learners feel stimulated to log in and participate. The header on the top of the page establishes the main purpose of the learning network 'helping you improve your reading, writing and number skills'. The central part is concerned with ensuring learners understand the log in process. The section to the left, offers an introductory video that graphically illustrates the features and functions of the site, including how to log in. Meanwhile, the section on the right hand side is all about numbers: members currently online, total number of registered learners, and qualifications achieved so far. The bottom section of the page shows a number of logos. These design elements together convey an image of a successful and supportive network. Many adult learners lack the confidence to engage in learning due to frustrated educational experiences in the past. In this context, the elements 
showing the high number of members and of qualifications achieved by Level 2 learners, may act as encouraging features. Further, by being able to see that there are other people online, learners who usually juggle jobs and family duties may feel more encouraged to persist. The logos may be seen as evocative of official endorsement for the learning network. Everything, represented in the various elements in the set design, is combined together with the aim of enabling and supporting learners to log in and learn.

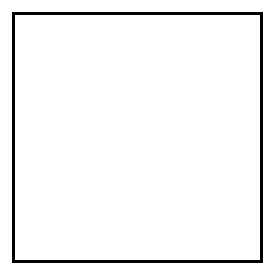

\section{Figure 3: Write On Welcome page}

Figure 4 shows a screenshot of another 'Write On' page, which is presented to learners once they have logged in. This page uses text and audio support to help learners decide which level they find appropriate to start at.

Apart from the image in the central part of the screen, all the other four sections of the page are the same as in the previous screen. Interestingly, all analytical designable dimensions (set, epistemic, social) can be identified within the design of this single central image. Some of the (set) elements we could analyse in the composition of this image would be: the speech bubbles with written and audio texts, the adult people, and the background with windows that create a connection to nature. In relation to epistemic design, within the speech bubbles, texts indicate knowledge and ways of knowing valued in the network (writing full sentences, reading with fluency, lifelong learning, etc.). On the social design level, the adults depicted in the image send a 'message' that this is a site for adults, and these are 'friendly people like you and me’. 


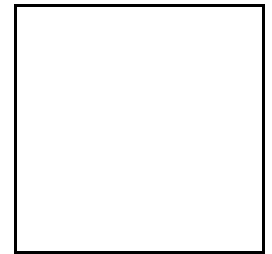

\section{Figure 4: Write On second page}

After choosing a level and completing a pre-assessment, learners are directed to a lesson page that presents them with a personalised learning path. This learning path represents a very interesting design feature. The screenshot in Figure 5 shows the learning path for Level 2.

The learning path is shown as a sophisticated interactive graphic, supported by audio, which helps learners to keep track of their progress. It allows learners to see at a glance which lessons have been completed, the unfinished ones (stripped squares), and those still to be started. It also shows how far learners are from completing minor (end of each path line) and major (30 points) awards.

Additionally, it allows learners to return directly to the lesson or assessment screen they left after a break. Thus, the learning path's primary purpose is to provide learners with an easy way to navigate through the learning materials. The graphical representation makes this process simpler and more effective.

This learning path represents an elaborated solution from a design perspective. Such a representation is an example of an important technique used to reify activities in a way that turns them into 'concrete' objects visible to learners (Pinto 2014). Every time a learner chooses a lesson, their activities are continuously reified and the elements in set design are re-arranged accordingly. In this sense, the learner's unfolding activity recreates the set design; the reified forms allow learners to communicate with the system in ways to cocreate and co-configure their learning place. By keeping track of their activities, learners are better positioned to reflect on their progress and make decisions on how to proceed. The spatial representation influences both subsequent activity and the setting through interwoven processes of reification and learners' construction of meaning. Strategies such as this may be particularly useful in webbased learning when, at least in theory, learners rely exclusively on the setting to learn. Unlike the traditional classroom where a teacher 
and classmates may enrich the learning experience, independent online learners mainly interact with digital and physical resources.

Interestingly, according to the designer interviewed for this study, the learning path plays additional useful roles in blended learning contexts. When Write On is used within schools or community centres, the learning path often seems to generate extra motivation through 'friendly rivalries' between learners. Analysis of interview data with learners and tutors, collected by NALA, revealed that some learners kept on doing activities to 'beat' classmates, that is, to make their figures in each path reach the end of the line before someone else's did. Furthermore, the learning path sometimes forged collaboration among students and/or between these and their children. For instance, interview data also revealed that some adult learners could count on getting effective help from their children, who seem to love the 'game feel' of the learning path. These examples are illustrative of the value of designers considering the social-materiality of learning, as discussed earlier in this paper. The learning path was designed after results of usability tests conducted by NALA indicated that the original long list with the sequencing of activities proved too hard for most learners to read and understand. As can be seen, the designed solution goes far beyond simply helping learners selfadministrate their lessons. Thus, a designed solution such as the learning path constitutes a good candidate for abstraction and will be captured and shared through design patterns to inform and facilitate design of similar enterprises.

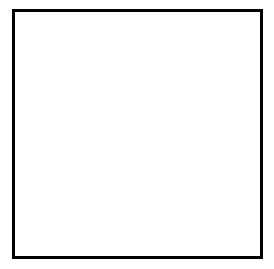

Figure 5: Learning path

\section{Implications}

In domains other than adult basic education, designers and teachers have been re-using good design ideas that have been captured and shared using pattern languages. Educational design 
research has been instrumental in supporting these collaborative practices (Laurillard 2012). As online networks catering for ABE start being created, good design practices can be captured in ways to start building a knowledge base to support, promote and facilitate designing processes in this field as well. Even though it may be too early to know which patterns are worth writing to create complete pattern languages for designing effective learning networks within the domain of adult basic education, new designs need not be developed from scratch. In all cases, pattern language theory points to the relevance of a holistic approach to analysis and design. In addition to its ideas about the advantages of sharing good design, pattern language theory is also very useful for its emphasis on the importance of paying attention to human values and emotions. In both formal and informal situations, it is not uncommon to find settings using technologies in ways that are neither conducive to learning nor pleasant. These usually are overwhelmingly flashing, busy and noisy spaces. Therefore, pattern language theory also serves as a good reminder that technologies must be seen as tools rather than the drivers of design for learning. Thus, understanding the interactions between the learners, the infrastructure and the wider environment requires considering, amongst other things, the role of design and mediating artefacts in affording or constraining learning experiences. The analytical work presented in this paper has illustrated how a systematic analysis coupled with different forms of representation and a common language can help in identifying and communicating good design solutions.

\section{Conclusion}

It was not the purpose of this study to elaborate on any specific approach to literacy teaching and learning. Instead, using a design perspective, the aim was to identify good design solutions that can be adopted and adapted for the creation of productive networked learning opportunities within both formal and informal adult basic education contexts. An important role of literacy education is to facilitate connections between members of the community so they can support each other in their daily lives. Appropriately designed environments can give adult literacy learners a chance to take part in online sessions that can help improve not only their reading and writing skills but also their lives. In this sense, networked learning may play a role in a more democratic distribution of social capital and 
in enabling people to critically evaluate, challenge and change social injustices. 


\section{References}

Alexander, C, Ishikawa, S, and Silverstein, M with Jacobson, M, Fiksdahl-King, I and Angel, S (1977) A Pattern Language: Towns, buildings, construction, Oxford University Press, New York.

Alexander, C (1979) The Timeless Way of Building, Oxford University Press, New York.

Alexander, C (2006) The Nature of Order, Center for Environmental Structure, Berkeley CA.

Barton, D, Hamilton, M and Ivanic, R, eds (1999) Situated Literacies, Routledge, London.

Barton, D and Hamilton, M (2005) Literacy, Reification and the Dynamics of Social Interaction, in Barton, D and Tusting, K, eds, Beyond Communities of Practice: Language, power and social context, Cambridge University Press, Cambridge, pp 1435. doi: http://dx.doi.org/10.1017/CBO9780511610554

http://dx.doi.org/10.1017/CBO9780511610554.003

Brandt, D and Clinton, K (2002) Limits of the Local: Expanding perspectives on literacy as a social practice, Journal of Literacy Research, vol 34, no 3, pp 337-356. doi: http://dx.doi.org/10.1207/s15548430jlr3403_4

Carvalho, C and Goodyear, P (2014) The Architecture of Productive Learning Networks, Routledge, New York.

Chovanec, M and Meckelborg, A (2011) Social Networking Sites and Adult Literacy: Raising the issues, retrieved 1 December 2012 from http://alphaplus.ca/en/web-tools/tech-podcastsgroup1/tech-podcasts.html

Jones, C and Dirckinck-Holmfeld, L (2009) Analysing Networked Learning Practices, in Dirckinck-Holmfeld, L, Jones, C, Lindstrom, B, eds, Analysing Networked Learning Practices in Higher Education and Continuing Professional Development, Sense, Rotterdam, pp 1-27.

Fenwick, T (2012) Matterings of Knowing and Doing: Sociomaterial approaches to understanding practice, Practice, Learning and Change, Springer, Netherlands, pp 67-83.

Goodyear, P, Banks, S, Hodgson, V and McConnell, D (2004) Research on Network Learning: An overview, in Goodyear, P, Banks, S, Hodgson, V and McDonnell, D, eds, Advances in Research on Networked Learning, Kluwer Academic 
Publishers, Dordrecht, pp 1-10. doi:

http://dx.doi.org/10.1007/1-4020-7909-5_1

Goodyear, P (2005) Educational Design and Networked Learning:

Patterns, pattern languages and design practice, Australasian

Journal of Educational Technology, vol 21, no 1, p 20.

Goodyear, P and Retalis, S (2010) Technology-Enhanced Learning,

Sense, Rotterdam.

Goodyear, P and Carvalho, L (2013) The Analysis of Complex

Learning Environments, in Beetham, $\mathrm{H}$ and Sharpe, R, eds,

Rethinking Pedagogy for a Digital Age: Designing and

delivering e-learning, Routledge, New York, pp 49-63.

Goodyear, P, Thompson, K, Ashe, D, Pinto, A, Carvalho, C, Parisio, M, Parker, P, Schwendimann, B, Wardak, D and Yeoman, P (forthcoming) Analysing the Structural Properties of Learning Networks: Architectural insights into buildable forms, in Mor, Y, Maina, M and Craft, B, eds, Art and Science of Learning Design, Sense, Rotterdam.

Laurillard, D (2012) Teaching as a Design Science: Building pedagogical patterns for learning and technology, Routledge, Abingdon.

McConnell, D, Hodgson, V and Dirckinck-Holmfeld, L (2011)

Networked Learning: A brief history and new trends, in

Dirckinck-Holmfeld, L, Hodgson, V and McConnell, D, eds, Exploring the Theory, Pedagogy and Practice of Networked Learning, Springer, New York, pp 3-24.

National Adult Literacy Agency (NALA): http://www.nala.ie

Pinto, A, Thompson, K, Jones, C and Clow, D (2014), iSpot: Your place to share nature, in Carvalho, $\mathrm{L}$ and Goodyear, $\mathrm{P}$, eds, The Architecture of Productive Learning Networks, Routledge, New York, pp 225-238.

Pinto, A (2014) Design and the Functioning of a Productive Learning Network, in Bayne, S, Jones, C, de Laat, M, Ryberg, T and Sinclair, C, eds, 9th International Conference on Networked Learning, Edinburgh, 7-9 April, pp 220-227.

Silver-Pacuilla, H (2008) Investigating the Language and Literacy

Skills Required for Independent Online Learning, National Institute for Literacy, Washington DC.

Smithe, S (2012) Incorporating Digital Technologies in Adult Basic Education: Concepts, practices and recommendations, AlphaPlus, Toronto, ON. 
Sørensen, E (2009) The Materiality of Learning: Technology and knowledge in educational practice, Cambridge University Press, Cambridge.

Street, B (1984) Literacy in Theory and Practice, Cambridge University Press, Cambridge.

Warschauer, M and Liaw, M L (2010) Emerging Technologies in Adult Literacy and Language Education, National Institute for Literacy, Washington DC.

Wenger, E (1998) Communities of Practice: Learning, meaning, and identity, Cambridge University Press, Cambridge. doi: http://dx.doi.org/10.1017/CBO9780511803932

Write On www.writeon.ie 
